\title{
Cavitary Tuberculosis
}

\section{Tatiana Denega MD}

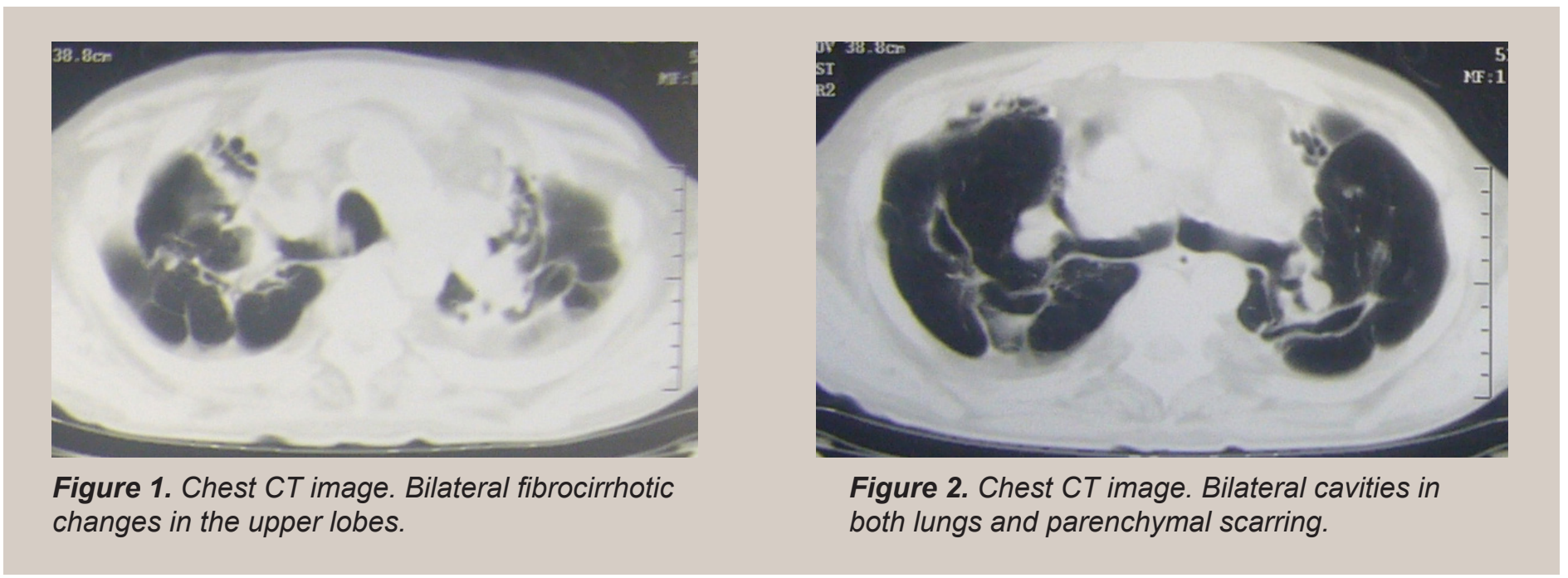

In November, 2008, a 58-year-old man was admitted to the Phthisiopulmonology clinic in Moscow, Russia, for the treatment of pulmonary tuberculosis (TB). The patient had hemoptysis, productive cough with mucopurulent sputum, dyspnea at rest, general malaise, and poor appetite. At age 17, pulmonary tuberculosis was diagnosed and successfully treated with the standard course of anti-tuberculous medication. At age 27, his tuberculosis relapsed with an infiltrate in the right lung. At age 35, cavitary tuberculosis of both upper lobes was diagnosed. At age 45 , drug resistant (isoniazid and rifampin) tuberculosis was diagnosed. At age 57, the patient was hospitalized at a local TB clinic due to increasing dyspnea on exertion and fatigue. The chest $x$-ray revealed the formation of a giant cavity in the left lung with severe
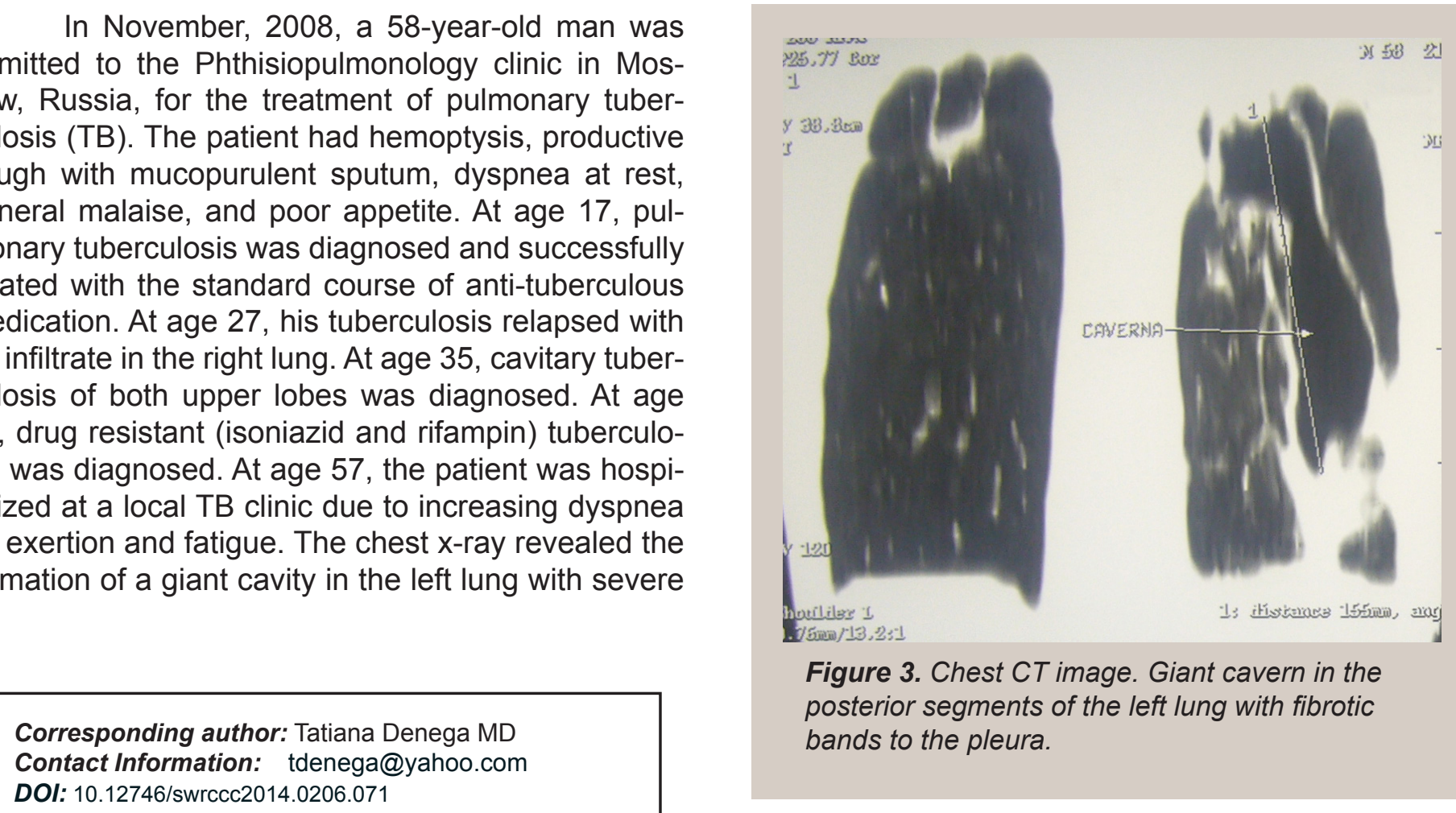

Figure 3. Chest CT image. Giant cavern in the posterior segments of the left lung with fibrotic bands to the pleura. 
fibrous distortion of pulmonary architecture. He was treated according to the drug susceptibilities of the TB isolate but voluntarily left the clinic when symptoms alleviated. In October, 2008, at age 58, the patient was alarmed by the hemoptysis with bright red blood (two to three tablespoons). He sought treatment at the TB clinic where CT imaging of the lungs was performed, and he was referred to the Phthisiopulmonology clinic. See Figures 1-3 for chest CT images.

\section{Discussion}

The natural host defense response to mycobacterial infection is the formation of granulomatous inflammation in an effort to isolate the tuberculous infection. This defense response is a synergetic complex immune response of macrophages, lymphocytes, and cytokines that eliminates the pathogens and forms the fibrous tissue with dystrophic calcification of caseous tubercles. ${ }^{1}$ Massive TB infection or inadequate treatment of the infection with the development of drug resistant tuberculosis may impact the course of infection and result in the persistence and progression inflammation leading to lung destruction.

Liquefaction of the caseous masses is the principal factor in the development ofcavitary pulmonary tuberculosis. The exact mechanismtriggering liquefaction is unclear. Several host factors, including neutrophil and macrophage metalloproteinases, macrophage-derived enzymes, and tumor necrosis factor, are involved in the formation of the cavities. ${ }^{2,6}$ Expanding soft necrotic masses fill the cavity until this material is evacuated through adjacent bronchi, resulting in cavity formation. ${ }^{1,7}$ The newly formed cavity, limited by pericavitary inflammation, is often found in one or two pulmonary segments. ${ }^{3,5}$ The inner wall of the cavity consists of caseous necrosis encapsulated by granular tissue and a thin fibrous outer layer. ${ }^{5} \mathrm{My}$ cobacteria colonies proliferate at the lining of the inner wall, highlighting the high potential for the spread of the infection. ${ }^{4,7}$ In the absence of the evacuation of necrotic masses, pericavitary inflammation may follow by the dissemination of the infection and the creation of new cavities that can fuse and expand throughout the lobe. ${ }^{3}$ Giant caverns often expand into the lobe and eventually throughout the lung with a significant deformation of the lung parenchyma. ${ }^{5}$ Persistent infection and recurring exacerbations stimulate the growth and thickening of the fibrous outer layer, which deforms the shape of the cavity and the surrounding lung tissue. ${ }^{3,4,5}$ Extensive pericavernous inflammation, multiple foci of dissemination, and pleural thickening characterize the transformation of the infection into the advanced cavernous tuberculosisand results in a significant deterioration of pulmonary function. ${ }^{4,5}$

Our patient's 30-year history of pulmonary tuberculosis with constant non-adherence to the treatment and numerous interruptions of the antituberculosis medication regimen led to the formation of multiple cavities in both lungs with the intensive fibrotic changes and restructuring of the lung tissue. The leading complications associated with chronic cavitary tuberculosis include the development of pulmonary hypertension with the consequent cor pulmonale, respiratory failure, and amyloidosis.

Recieved : $12 / 29 / 2013$

Accepted : 02/24/2014

Reviewers : Kenneth Nugent MD

Published electronically : 04/15/2014

\section{REFERENCES}

1. Kumar V, Abbas AK, Fausto N, Aster JC. Robbins and Cotran Pathologic basis of disease. 8th edition. W.B. Sounders Elsevier. 2010, p 664-674

2. Yoder MA, Lamichhane G, Bishai WR. Cavitary pulmonary tuberculosis: The Holy Grail of disease transmission. Current science, Vol.86, No1, 10 Jan 2004

3. Rosenshtrauch LS, Ribakova NI, Vinner MG (1987). Radiodiagnosis of respiratory system diseases: Physicians Manual (2nd ed.) (p. 629-630). Moscow: Medicine (Russian) 
4. Sokolov VA, Skornyakov SN, Grinberg LM. (2002) Fibrouscavernous and cirrhotic tuberculosis of lungs. Part 1. Manual for phthisiatricians, pulmonologists, rhoentgenologists. (p.2-19). Ekaterinburg (Russian)

5. Strukov AI, Soloveva IP (1986) Morphology of tuberculosis in modern conditions. (2nd ed.) (p. 76-118) Moscow: Medicine (Russian)

6. Oral Abstract Session: Biomarkers of Infectious Diseases. Tissue destruction and cavitation: Neutrophils wield a doubleedged sword in human pulmonary tuberculosis. C. Ong, P. Elkington, C. Ugarte-Gil, L. Tezera,R. Gilman, J. Porter, J. S. Friedland

October 5, 2013.

7. Davis PDO, Barnes PF, Gordon SB (2008). Clinical tuberculosis. (4th ed.) Taylor\&Francies group. (p.109-111) 